\title{
A Mixed-Methods Investigation of the Relationship between Critical Thinking and Library Anxiety among Undergraduate Students in their Information Search Process
}

\author{
Nahyun Kwon
}

\begin{abstract}
This study investigated the nature of associations between critical thinking dispositions and library anxiety among 137 undergraduate students. The study was conducted by administering standardized survey instruments and by analyzing the contents of student essays on critical incidents of their library use experience. The results of these quantitative and qualitative investigations consolidated each other by revealing negative associations between the two variables. An interactive model of critical thinking and library anxiety emerged from the investigation, showing how they interact with each other during the library use process. Both theoretical and practical implications of the findings were discussed within the frameworks of affective information behavior and information literacy, respectively.
\end{abstract}

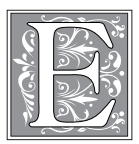

nabling students to think critically is one of the major goals of higher education. ${ }^{1}$ Critical use of information resources is fundamental to higher education; therefore, tertiary institutions stress students' abilities to use libraries and information resources critically. With the new generation of computer-literate students and the vast amount of information available in both print and electronic formats, ${ }^{3}$ the necessity to develop the ability to use information resources in the library is paramount. Consequently, academic libraries now assume a far greater role in assisting students to locate and evaluate information critically by teaching information literacy.

Indeed, the search for information involves critical thinking. ${ }^{4}$ Due to the importance of analytical and systematic thinking skills in using libraries, critical thinking has been of interest to both information literacy instructors and library and information science (LIS) researchers. For example, Sonia Bodi maintained that teaching critical thinking skills is an important component of bibliographic instruction. ${ }^{5}$ Ethelene Whitmire reported that library use is an environmental fac-

Nahyun Kwon is Assistant Professor in the School of Library and Information Science, College of Arts $\mathcal{E}$ Sciences at University of South Florida; e-mail: nkwon@cas.usf.edu. The author would like to thank Ms. Sonia Wohlmuth and Ms. Kiersty Cox for their generous supports in recruiting students for this study. 
tor that enhances critical thinking skills. ${ }^{6}$ These studies examined critical thinking either as an important component of information literacy education or as an outcome of library use.

While critical thinking is typically associated with cognitive abilities and skills, the ideal critical thinker is also characterized by how s/he approaches life in general or a specific problem at hand. ${ }^{7}$ This indicates that critical thinking relates not only to cognitive abilities but also to affective dispositions. Peter Facione and his colleagues defined the disposition toward critical thinking as "the consistent internal motivation to use critical thinking skills to decide what to believe and what to do" when one approaches problems, ideas, decisions, or issues. ${ }^{8}$ Accordingly, students with strong critical thinking dispositions tend to have more positive attitudes toward their own critical thinking abilities and are open to unfamiliar situations or ideas. Conversely, students' negative attitudes and mistrust about their own thinking abilities could cause illogical fear and inadequacy in performing academic activities. More important, critical thinking skills and dispositions are considered to be highly related. ${ }^{9}$ This observation suggests that students equipped with more positive dispositions tend to demonstrate better critical thinking skills, whereas students with negative dispositions tend to exhibit poorer critical thinking skills.

The critical use of academic library resources is important for college students to achieve high academic performance. ${ }^{10}$ Unfortunately, LIS literature reports the prevalence of illogical or inadequate feelings or attitudes toward the use of the library, known as library anxiety, among college students. ${ }^{11}$ Researchers have demonstrated empirically that library anxiety debilitates effective use of libraries and information resources. ${ }^{12}$ This suggests that library anxiety may impede cognitive processes during the information search process in the library.

While both library anxiety and critical thinking dispositions seem to affect cognitive processes during information searches, little is known about the nature of their association during the library research process. Only recently, Nahyun Kwon, Anthony Onwuegbuzie, and Linda Alexander revealed a negative association between library anxiety and critical thinking dispositions among graduate students. ${ }^{13}$ However, no research, to date, has investigated the nature of their association. The association has yet to be investigated for undergraduate students who are, in fact, the primary target population of the academic library's information literacy programs. Therefore, the present study was designed to investigate the underlying mechanism that can explain the association between library anxiety and critical thinking disposition by undertaking both quantitative and qualitative approaches. The findings will be able to explain how critical thinking and library anxiety interact with each other and, ultimately, assist with developing useful directions for information literacy programs.

\section{Method \\ Participants}

Participants were undergraduate students enrolled in one of six sections of Library and Internet Research Skills at a state university in southeastern United States. It is a three-credit course that teaches the research skills needed to identify, select, and evaluate appropriate print and Internet-based documents and databases to answer education, research, and other information needs. This course emphasizes the development of critical thinking skills in relation to the use and application of information. A total of 180 students enrolled either as a required or an elective course during the spring 2006 semester, and 137 students participated in the study during the first two weeks of the semester on a voluntary basis. Approximately, 68.9 percent of the 137 participants were female. Ages of the participants ranged from 18 to 60 years $($ Mean $=22.9, S D=6.9)$. The majority of the participants were White 
(77.8\%), followed by African American $(13.3 \%)$, Hispanic $(4.4 \%)$, Asian/Pacific Islanders $(3.0 \%)$. Class rankings were freshmen $(6.0 \%)$, sophomore $(27.6 \%)$, junior (41.8\%), and senior (21.6\%).

\section{Data Collection Techniques for Quantita- tive and Qualitative Investigations}

The present study employed both quantitative and qualitative data collection methods as described below. First, for quantitative investigations, participants were administered the California Critical Thinking Disposition Inventory (CCTDI) and Library Anxiety Scale (LAS). The CCTDI was developed by Peter Facione and Noreen Facione to measure a person's disposition to use critical thinking. ${ }^{14}$ This instrument measures the following seven dimensions of critical thinking dispositions: (a) truth-seeking; (b) open-mindedness; (c) analyticity; (d) systematicity; (e) critical thinking self-confidence; (f) inquisitiveness; and (g) maturity. Truthseeking represents the disposition of being keen to seek the truth, audacious about asking questions, and honest and objective about seeking inquiry even if the findings do not support one's preference or one's preconceived opinions. Open-mindedness refers to the disposition of being tolerant of divergent opinions and being sensitive to the possibility of one's own bias. Analyticity represents the disposition of being cognizant of potentially problematic situations, anticipating possible findings or consequences, and valuing the application of reason and the use of evidence even if the underlying problem emerges as being difficult or challenging. Systematicity is the disposition toward organized, logical, focused, and attentive inquiry. Critical thinking self-confidence refers to the level of self-assurance one has regarding one's own reasoning processes. Inquisitiveness relates to one's intellectual curiosity. Finally, maturity denotes how disposed a person is to make reflective decisions when facing ill-structured problem situations. ${ }^{15}$ The CCTDI contains 75 items measured on a six-point Likert- type scale anchored with 1 being "agree strongly" and 6 being "disagree strongly." A higher score on this scale represents more positive critical thinking dispositions. For the current investigation, the dimensions generated scores for the sample that had a classical theory alpha reliability coefficient of .78 for truth-seeking, .65 for open-mindedness, .71 for analyticity, .62 for systematicity, .84 for critical thinking self-confidence, .81 for inquisitiveness, and .69 for maturity.

Library anxiety was measured by administering the Library Anxiety Scale (LAS) developed by Sharon Bostick. ${ }^{16}$ This scale contains the following five dimensions: (a) barriers with staff; (b) affective barriers; (c) comfort with the library; (d) knowledge of the library; and (e) mechanical barriers. Barriers with staff refer to students' negative perceptions and beliefs that librarians are threatening, frightening, unapproachable, and inaccessible when the students are in need of personal assistance from the librarians. Affective barriers pertain to students' feelings of inadequacy while completing library tasks. These feelings of ineptness are aggravated by the ungrounded assumption that their fellow students are more capable library users than they are. Comfort with the library represents how comfortable, welcoming, secure, safe, and nonthreatening students perceive the library to be. Knowledge of the library pertains to the degree of familiarity students feel with the library. Finally, mechanical barriers denotes uncomfortable feelings that stem from using library equipment and machines, including computers, computer printers, and photocopy machines. ${ }^{17}$ The LAS consists of 43 items that assess levels of library anxiety experienced by students on a 5-point Likert-type scale. A high score on any dimension represents high levels of anxiety in that area. For the present study, the dimensions generated scores for the sample that had a classical theory alpha reliability coefficient of .91 for barriers with staff, .86 for affective barriers, .75 for comfort with the library, 
.60 for knowledge of the library, and .72 for mechanical barriers.

It should be noted that the use of the LAS has been questioned in the literature because of the limitation of its use in the current digital library environment. ${ }^{18}$ The scale was developed in 1992 mostly reflecting the physical library environment, and mechanical barriers, the fifth dimension of the scale, in particular, do not adequately measure the current technology in the digital library. There have been efforts to resolve this concern by developing an undated scale, such as Doris Van Kampen's Multidimensional Library Anxiety Scale (MLAS) ${ }^{19}$ and Snunith Shoham and Diane Mizrachi's Hebrew-Library Anxiety Scale (H-LAS). ${ }^{20}$ These scales, however, were designed with somewhat limited purposes, measuring library anxiety among graduate students in the process of thesis writing or among students in non-English-speaking countries. None of these newly developed scales have demonstrated general applicability yet, while the LAS still is a highly robust, validated scale that can measure library anxiety of the undergraduate students in the United States. Thus, despite the known limitations, it was decided to use the LAS for the present study.

The dimensions of both CCTDI and LAS are recapitulated in table 1 with their classical theory alpha reliability coefficient scores generated for the study sample.

Second, for qualitative approach of the inquiry, students were asked to write an essay to report a critical incident from their past experience of library use following the instruction below:

Recall your most recent or most memorable experience of using the library and its resources to write a research a paper. Write an essay in 500-1,000 words describing your thoughts and feelings as you worked from the beginning of the assignment to its conclusion. What were you thinking and how did you feel when you used the library and its resources to find information for the research paper?

\section{Research Objectives and Hypotheses}

The first research objective of the present study was to investigate whether college students with weak critical thinking dispositions would have greater library anxiety than students with strong critical thinking dispositions. For this purpose, five research hypotheses were established. Specifically, students with weak critical thinking dispositions, compared to students with strong critical thinking disposition, would:

- feel greater barriers with staff in using the library (Hypothesis 1);

- have greater affective barriers in using the library (Hypothesis 2);

- have lower levels of comfort with the library (Hypothesis 3);

- feel greater apprehension about their insufficient knowledge of the library (Hypothesis 4); and

- feel greater mechanical barriers to using the library (Hypothesis 5).

The second objective of this research was to further explore the underlying mechanism that explains the association between critical thinking disposition and library anxiety by analyzing student essays. A specific focus was given to how the two interact as they move along the process of information searching in the library.

\section{Data Analysis}

The major analytical procedure used in this study included both quantitative and qualitative techniques. First, for the quantitative survey data, a series of t-tests were conducted using SPSS+ version $13.0^{21}$ to test specific research hypotheses that examined whether students with lower CCTDI scores have higher library anxiety scores than their counterparts with higher CCTDI scores. For the qualitative essay data, content analysis was conducted to obtain insight on the nature of the association between critical thinking dispositions and library anxiety. 


\begin{tabular}{|c|c|c|c|c|}
\hline \multicolumn{5}{|c|}{$\begin{array}{c}\text { TABLE } 1 \\
\text { Dimensions of Critical Thinking Dispositions and Library Anxiety } \\
\text { with Reliability Scores }\end{array}$} \\
\hline Dimensions & Definitions & $\begin{array}{l}\text { Reliability } \\
\qquad(\alpha)\end{array}$ & Mean & S.D. \\
\hline \multicolumn{2}{|c|}{ CCTDI 7 Dimensions } & .91 & & \\
\hline $\begin{array}{l}\text { Truth- } \\
\text { seeking }\end{array}$ & $\begin{array}{l}\text { Keen to seek the truth, audacious about } \\
\text { asking questions, and honest and objective } \\
\text { in asking questions }\end{array}$ & .78 & 34.56 & 6.38 \\
\hline $\begin{array}{l}\text { Open- } \\
\text { mindedness }\end{array}$ & $\begin{array}{l}\text { Open-minded and tolerant of divergent } \\
\text { opinions and honesty in facing one's own } \\
\text { bias }\end{array}$ & .65 & 30.12 & 5.75 \\
\hline Analyticity & $\begin{array}{l}\text { Cognizant of the potential for problematic } \\
\text { situations; values reason and the use of evi- } \\
\text { dence when facing challenging situations } \\
\text { rather than deciding on the basis of whim } \\
\text { or impulse }\end{array}$ & .71 & 28.15 & 5.58 \\
\hline Systematicity & $\begin{array}{l}\text { Care in focusing attention on the problem } \\
\text { at hand; approach problems in diligent, } \\
\text { focused, systematic, organized, logical, and } \\
\text { attentive inquiry; orderly in working with } \\
\text { complexity }\end{array}$ & .62 & 30.97 & 5.63 \\
\hline $\begin{array}{l}\text { CT Self- } \\
\text { confidence }\end{array}$ & $\begin{array}{l}\text { Self-assured regarding one's own reason- } \\
\text { ing processes, very comfortable with own } \\
\text { level of cognitive ability }\end{array}$ & .84 & 27.24 & 6.92 \\
\hline Inquisitiveness & $\begin{array}{l}\text { Intellectually curious, values being well- } \\
\text { informed and knowing how things work, } \\
\text { values learning; persistent through difficul- } \\
\text { ties are encountered }\end{array}$ & .81 & 28.32 & 5.95 \\
\hline Maturity & $\begin{array}{l}\text { Understands some problems to be ill-struc- } \\
\text { tured, therefore multiple ways to solve any } \\
\text { given problem }\end{array}$ & .69 & 30.72 & 6.54 \\
\hline \multicolumn{2}{|c|}{ LAS 5 Dimensions } & .93 & & \\
\hline $\begin{array}{l}\text { Barriers with } \\
\text { Staff }\end{array}$ & $\begin{array}{l}\text { Believes that librarians are threatening, } \\
\text { unapproachable, inaccessible, too busy } \\
\text { with duties to help students }\end{array}$ & .91 & 34.30 & 8.27 \\
\hline $\begin{array}{l}\text { Affective } \\
\text { Barriers }\end{array}$ & $\begin{array}{l}\text { Feels inadequate or inept in attempt- } \\
\text { ing library tasks, which are exacerbated } \\
\text { by assuming that other people are more } \\
\text { proficient }\end{array}$ & .86 & 30.31 & 7.45 \\
\hline $\begin{array}{l}\text { Comfort with } \\
\text { the Library }\end{array}$ & $\begin{array}{l}\text { Perceives the library as a comfortable, } \\
\text { welcoming, secure, safe, and non-threaten- } \\
\text { ing place }\end{array}$ & .75 & 18.53 & 3.85 \\
\hline $\begin{array}{l}\text { Knowledge of } \\
\text { the Library }\end{array}$ & $\begin{array}{l}\text { Degree to which students believe they are } \\
\text { familiar with the library }\end{array}$ & .60 & 10.47 & 2.69 \\
\hline $\begin{array}{l}\text { Mechanical } \\
\text { Barriers }\end{array}$ & $\begin{array}{l}\text { Discomfort stemming from using library } \\
\text { equipment, including computers, printers, } \\
\text { and photocopiers }\end{array}$ & .72 & 7.56 & 1.93 \\
\hline
\end{tabular}




\section{Results}

\section{Participant Characteristics}

The means and standard deviations pertaining to the critical thinking disposition and the library anxiety dimensions are presented in table 1 . To characterize the present sample, the sample was compared with the normative sample of the undergraduate students for their critical thinking disposition scores reported by the developers of the CCTDI. ${ }^{22}$ According to their report, individuals who score below 40 on a given scale are weak with respect to that critical thinking dispositional component, whereas individuals who score above 50 on a given scale are strong with respect to that critical thinking dispositional component. The proportion of students who scored below 40 on each critical thinking dispositional dimension for the present study versus a normative sample of undergraduate students $(n=267)$ reported by the CCTDI developers was, respectively, as follows: truth-seeking ( $82 \%$ vs. $60 \%)$, open-mindedness (50\% vs. $15 \%$ ), analyticity ( $42 \%$ vs. $23 \%$ ), systematicity ( $63 \%$ vs. $44 \%$ ), critical thinking self-confidence (38\% vs. $25 \%$ ), inquisitiveness ( $45 \%$ vs. $14 \%$ ), maturity
(55\% vs. $17 \%$ ), and CCTDI total $(49 \%$ vs. $22 \%$ ). More students were classified weaker in their critical thinking in the present study than the normative sample across all seven scales. This informs that the sample was characterized by lowerthan-average levels of critical thinking dispositions.

\section{Quantitative Investigations}

The five research hypotheses were tested to examine whether college students with weak critical thinking dispositions (CTD) would have greater library anxiety than students with strong CTD in each of the five areas of library anxiety. For this purpose, the participants were first divided into three equal groups with respect to their total CCTDI score (that is, high, medium, and low CTD groups), which were ranged from 229 to 357 (Mean $=282.2 ; S D$ $=30.5$ ) among the study sample. To compare students with strong and weak CTD, students in either high or low CTD groups were selected for analysis. Students who scored 300 or above were categorized as the strong CTD group $(n=37)$, whereas students who scored 264 or below were assigned as the weak CTD group $(n=37)$.

\begin{tabular}{|c|c|c|c|c|}
\hline \multicolumn{5}{|c|}{$\begin{array}{c}\text { TABLE } 2 \\
\text { Comparisons of Library Anxiety Between Strong and Weak Critical } \\
\text { Thinking Disposition (CTD) Groups }(\mathrm{N}=74)\end{array}$} \\
\hline \multirow{2}{*}{\begin{tabular}{l|l} 
Library \\
Anxiety \\
Dimensions
\end{tabular}} & \multicolumn{2}{|c|}{ Library Anxiety Mean Score } & \multirow{2}{*}{$\begin{array}{l}\text { Difference in } \\
\text { Library } \\
\text { Anxiety Between } \\
\text { Groups } \\
\end{array}$} & \multirow[t]{2}{*}{$\mathrm{t}^{\mathrm{a}}$} \\
\hline & $\begin{array}{c}\text { Strong CTD } \\
\text { Group }(\mathrm{n}=37)\end{array}$ & $\begin{array}{c}\text { Weak CTD } \\
\text { Group }(n=37)\end{array}$ & & \\
\hline Barriers with Staff & 30.88 & 38.20 & 7.32 & $3.483 * * *$ \\
\hline Affective Barriers & 27.24 & 32.94 & 5.70 & $3.127 * *$ \\
\hline $\begin{array}{l}\text { Comfort with the } \\
\text { Library }\end{array}$ & 16.97 & 20.09 & 3.12 & $3.230 * *$ \\
\hline $\begin{array}{l}\text { Knowledge of the } \\
\text { Library }\end{array}$ & 9.17 & 11.72 & 2.55 & $4.191 * * *$ \\
\hline Mechanical Barriers & 7.23 & 8.06 & .83 & $1.761 *$ \\
\hline $\begin{array}{l}\text { Overall Library } \\
\text { Anxiety }\end{array}$ & 93.03 & 111.13 & 18.10 & $3.824 * * *$ \\
\hline
\end{tabular}


Subsequently, the weak CTD group was compared with the strong CTD group for their difference in each of the five library anxiety areas. The tests were conducted using a series of independent sample t-tests at the .05 significance level. Test results are presented in table 2.

The average library anxiety scores between the strong and weak CTD groups were compared, respectively, as follows: barriers with staff ( 30.9 vs. 38.2); affective barriers (27.2 vs. 32.9$)$; comfort with the library (17.0 vs. 20.1); knowledge of the library (9.2 vs. 11.7); and mechanical barriers (7.2 vs. 8.1). Library anxiety scores were consistently higher among the weak CTD group across all five LAS dimensions. The t-test results supported all five research hypotheses, revealing that, across all five LAS dimensions, students with weak critical thinking dispositions tend to have a statistically higher level of library anxiety than students with strong critical thinking dispositions $(\alpha<.05)$. These test results from undergraduate students confirmed the finding of an earlier study that reported a negative association between the two affects among graduate students. ${ }^{23}$

\section{Qualitative Investigations}

The nature of the negative associations was investigated further by analyzing the contents of essays in which the participants reported a critical incident of their own library use in the past. This section describes general patterns that emerged from the content analysis in the sequence from the beginning to the end of the library task.

\section{Library Anxiety was Prevalent Among Most College Students}

According to the narratives from the college students participating in this study, regardless of their critical thinking disposition scores, library anxiety seems to be a common experience to most students in the beginning of their library use. Sarah (19, sophomore) who was categorized into the weak CTD group expressed her initial feeling as, "I would not say that libraries intimidate me, but I would say that they overwhelm me to the extent that I avoid them altogether.... my biggest shame is that I am clueless in the library. I don't know where to start when I have to research something not using the Internet." This feeling of being lost was also observed in Heather (27, senior) who was in the strong CTD group: "I was intimidated since I had never had to search for books in the library before. I was able to use the computer to find books that I wanted... I had no idea how the library was set up and it was like walking through a maze. I didn't want to ask a librarian for help because I felt foolish." As such, library anxiety, specifically affective barriers and barriers with staff, was prevalent among most college students participating in this study. It was rather surprising to learn that the narratives in the present study were very similar to those in Mellon's widely cited 20-year-old study where 75 percent to 85 percent of college students reported library anxiety. ${ }^{24}$ It was also interesting to see that participants, including the aforementioned students, often compared their library use to Internet searching, in which they seemed to feel more capable and comfortable when looking for information.

\section{Library Anxiety Hampered Critical Thinking Skills}

Indeed, there were constant indications that library anxiety, a negative affect, hampered critical thinking skills and abilities that were supposed to be utilized to search for information. The aforementioned Sarah, who is in the weak CTD group, went on to say: "When I went into the library, I was immediately confused about which floor to go to, and the confusion quickly led to frustration. I do feel that I possess a very high level of thinking and logic[cal] skills but my patience with 'where do I even start' is what makes me most uneasy at the library." Just like Sarah, many study participants felt that their thinking capability was hampered 
by their feelings of being lost and anxious. A similar experience was shared by a male student Matt (19, sophomore, in the weak CTD group) who stated that his feeling of being lost debilitated his normal thinking abilities: "When I first started my research, I felt like I was lost in a sea. I didn't know where to start.... For a few minutes I felt like my thinking abilities were gone." This phenomenon may be explained by Diane Nahl, who contended that negative affective states (such as frustration, low expectations, pessimism, low self-efficacy, and low motivation) disrupt cognitive strategies.

Although Matt stated that his anxiety had hampered his thinking abilities, interestingly, his subsequent statement hinted at a transition away from the anxiety. It was his efforts to make sense out of nonsense that led him to move forward to the proper path: "I was just looking around blank, trying to figure a way to start my research ... after walking around a few laps, I had more self-esteem about finding stuff." This critical spirit or positive critical thinking disposition ("trying to figure a way to start my research") was activated when facing challenges, which, in turn, served as a force to reinstate the hampered critical thinking skills. This noteworthy transition is described in further detail below.

\section{Critical Thinking Dispositions Helped to Reinstate Critical Thinking Abilities and to Reduce Anxiety}

The narratives in the student essays showed that students tend to take various approaches when they encountered feelings of being lost and the subsequent cognitive incapability of pursuing the problem at hand. Jen (22, senior) noted her experience as follows:

When I first walked in[to] the library I was intimidated. It was a little bigger than what I was used to. Once I took a couple of deep breaths I realized that it was still a library and I have been using them since elementary school. When I finally calmed my nerves, I had no problem finding the information that I was looking for. ... I knew I could find plenty of resource material to research.

Jen's efforts to tackle the problem can be attributed to her disposition to approach the problem logically ("took a couple of deep breaths"; "calmed my nerves") and self-confidence toward her critical thinking ability ("I knew I could find plenty of resource material to research"), which helped lower her affective barriers to the library and eventually resolve the problem.

Some students expressed apprehension in using the library because they had never used the library before to find information. However, strong critical thinking dispositions of systematicity enabled them to figure their way out:

...I had no idea how the library was set up and it was like walking through a maze. I didn't want to ask a librarian for help because I felt foolish. Eventually, I figured out the way the library was organized and found all of the books I wanted. ...I felt that my thinking abilities turned out well once I figured out where everything was and finally found my books. (Heather in the strong CTD group)

As such, while library anxiety was commonly reported in the narratives of novice college library users, a systematic approach to understanding the academic library's seemingly complex organization systems enabled students to bring their thinking capabilities back to normal.

Other students have attempted trying out different library resources and facilities when they felt barriers. This inquisitiveness, another aspect of critical thinking disposition, was observed frequently among students with strong CTD. This helped students quickly reinstate 
cognitive strategies that can help perform task-relevant activities: ${ }^{26}$

I will admit at first I was apprehensive and unsure of the steps to take and the route to go or where to find things. I took it upon myself to take a trip to the library to walk around and learn the layout and content of each floor, where help was located and the areas I would need to focus on and be in during my time there. Once I did that, I felt very comfortable to return and start my research process.... (Hudson in the strong CTD group)

According to Diane Nahl, positive affective states, such as critical thinking disposition in the current study, can "provide persistence and integration to cognitive strategies by managing ambiguity and cognitive loads." ${ }^{27}$

As shown, critical thinking dispositions helped reinstate the impeded critical thinking skills while reducing library anxiety. Some of the Facione's seven critical thinking disposition dimensions seem to be more frequently observed than others. These were critical thinking self-confidence, systematicity, and inquisitiveness. Indeed, these three dispositions were also reported to be particularly associated with library anxiety among graduate students. ${ }^{28}$

Positive critical thinking dispositions were generally observed among most students in their attempts to face the problems. However, the dispositions were not observed from some students, which tend to be the case more among those students with lower CCTDI scores. The following remarks were noted by a female sophomore who scored low in her CCTDI and high in her LAS: "When I first chose the story, I was confident that I could write a satisfactory essay. ... After three exhausting days of worrying and pretending my search was going well, I gave up... I had no good notes to refer to when I sat down to write the essay...
The resulting work was poor." None of the seven critical thinking dispositions were observed in her essay. Throughout, and without finding any breakthrough, this student remained weak in her critical thinking dispositions. In fact, her initial confidence in research and thinking abilities was diminished over time with her growing frustrations with the library. Just as with this student, some students, by not dealing with the negative feelings properly, remained clueless and hopeless.

In sum, the qualitative data analysis provided further explanations of the negative association between library anxiety and critical thinking by elucidating how the two concepts interact with one another in the library research process. This process was depicted in the Interactive Model of Critical Thinking and Library Anxiety in figure 1.

According to the model, college students generally feel library anxiety as a common experience with the initiation of an information search task in the library (Stages 1-2). Library anxiety, a negative affect, debilitates critical thinking skills and abilities (Stages 2-3). Facing this situation, positive critical thinking dispositions, a positive affect, are prompted in an effort to carry out the task when facing problems (Stage 4). These positive dispositions help reinstate the hampered critical thinking skills (Stage 5), reduce library anxiety (Stage 6), and possibly help the student find information relevant to the research task (Stage 7). While the first four stages appeared in a distinctive sequence in the student reports, the fifth and sixth stages appeared to occur almost simultaneously in the present study. Stage 7 was not actually assessed by objective data because the degree of relevancy of the behaviors could not be determined by subjective student reports. Thus, Stage 7 was only posited based on the student reports as well as the previous literature that reported that anxiety hinders performance due to illogical approaches to the problem. ${ }^{29}$ 
Critical Thinking Develops with the Use of College Libraries.

Besides the dynamic interaction between library anxiety and critical thinking, the qualitative investigation also revealed another notable finding. That is, critical thinking abilities and dispositions could change over time with the progression of research and library use. In the beginning, students generally expressed weak critical thinking self-confidence and library anxiety. However, after experiencing the library and the research process, students seemed to gain confidence in both library use and their thinking abilities: "As my research went on, I was more relaxed with my surroundings and my thinking abilities then expanded"; "The more I explored and used both I gained a comfort and understanding of both allowing my thinking abilities and skills to feel concrete and stable." As another student put it, "my thinking abilities and skills in the entire process were developed through the whole process."

It was not certain whether critical thinking skills were actually enhanced as the student reported, or whether the students just felt that their critical thinking skills, a cognitive domain, were enhanced. Nonetheless, the actual library use had certainly enhanced critical thinking self-confidence, an affective domain. Positive library use experience seems to help even the most frustrated students feel more relaxed and confident in their thinking skills: "It was during this instant that my relentless anxiety [of the library] started to change for the better. Right away, I was greeted by a warm and friendly librarian who put me at ease." (Laura, 24, junior) Indeed, positive experience with librarians lowered library anxiety, which, in turn, helped students perform the task properly. In short, it appears that both understanding the values of the library through the use of the service and positive experience with librarians helped assuage frustrations and build confidence. This finding could explain Whitmire's earlier cross-sectional 
survey finding that library use is a factor enhancing critical thinking skills. ${ }^{30}$

\section{Discussion}

Information seeking often involves critical thinking in identifying and evaluating relevant resources from a myriad of information sources and databases. While the associations between critical thinking and library anxiety are intuitive, few empirical studies have examined their dynamic associations to date. The present study investigated the nature of the associations between critical thinking dispositions and library anxiety among college students. The association was examined by collecting both quantitative and qualitative data sets from 137 undergraduate students at a southeastern research university.

Overall, the results of the quantitative and qualitative data analysis strengthened each other. The cross-sectional survey data showed that undergraduate students with weak CTD tend to have greater library anxiety. Specifically, students with weak CTD tend to (a) feel greater barriers in getting help from librarians; (b) feel greater inadequacy and frustrations in using the library; (c) perceive the library as less comfortable and more threatening; (d) feel less familiar with the library; and (e) feel greater frustrations in using library equipment. These findings about college students are largely consistent with the finding of an earlier study that revealed a negative association between the two affects among graduate students. ${ }^{31}$

The negative associations between library anxiety and critical thinking dispositions were also observed through content analysis of students' narratives regarding their library use experience. Triangulating the results from the qualitative investigation provided rich explanations of the quantitative part of the investigation. Furthermore, the qualitative investigation enabled the researcher to identify a model that illustrates dynamic interactions between the two affects (i.e., library anxiety and critical thinking dispositions) and their relationships with critical think- ing skills (figure 1). In fact, these dynamic interactions strengthen the claims made in the framework of Kuhlthau's information-search process (ISP). ${ }^{32}$ Unlike most conceptual models of information seeking, where the cognitive aspect of the search process is highlighted, the ISP illustrates how affective states, such as anxiety and confusion, could hinder performance by interacting with cognitive stages.

Probably a very notable but disturbing finding, as indicated in the model, is that most students in the present study expressed uneasy feelings with the initiation of library task. This phenomenon, confirming Mellon's two-decade-old study finding that most college freshmen suffered from library anxiety, informs that library anxiety still is a hindrance for many Millennials, ${ }^{33}$ the new generation that was born in 1982 or after and known to be technologically savvy and proficient, to perform their library task.

More important, the proposed model depicts a pivotal role of critical thinking dispositions in the information search process by illustrating their influences on the subsequent cognitive and affective states. When strong critical thinking dispositions were present, the critical thinking skills hampered by library anxiety were reinstated and library anxiety was diminished. Accordingly, students seemed to perform behaviors that were relevant to carry out their research tasks (i.e., find relevant information). A different mechanism was observed when strong critical thinking dispositions were not present. Michelle, who was weak in critical thinking disposition, wrote, "I was lost in the library... There was nothing about this experience that made me feel confident in my thinking abilities or writing skills... After three exhausting days of worrying and pretending my search was going well, I gave up." Because her positive dispositions were not activated properly to handle her negative emotion when facing a problem, she remained apprehensive and seemed to have failed to find information relevant to her task. 
The above findings revealed how critical thinking dispositions work in carrying out information search tasks. From this result, it can be contended that critical thinking dispositions are the key factor that activates cognitive capabilities (that is, critical thinking abilities) and regulates negative emotions (that is, library anxiety). It can also be contended that critical thinking disposition is a catalyst that can change the information search process from frustration to hope. This finding further suggests the importance of positive affect in carrying out the information task successfully.

The results of the present study strengthen the claims made by Diane Nahl's affective load theory in which negative affective states disrupt cognitive strategies, interrupt the search, and often bring a premature termination, whereas positive affective states command persistence and integration to cognitive strategies by handling ambiguity and cognitive loads properly. ${ }^{34}$ According to Alice Isen, Kimberly Daubman, and Joyce Gorgoglione, positive affect facilitates learning by making simplifying the task and making research more efficient. ${ }^{35}$ The underlying mechanism is that positive affect serves as a cue that retrieves positive material in memory and that, in turn, influences cognitive activities (that is, categorization, similarity, judgment, memory, decision-making, and creative problem solving) in unfamiliar contexts. This is because, when facing uncertainty, cues related to the existing body of knowledge become associated with the new knowledge and later are able to serve as effective cues for recall. This theoretical explanation is manifested in Jen's remark: "when I first walked in the library I was intimidated... Once I took a couple of deep breaths I realized that it was still a library and I have been using them since elementary school... I had no problem finding the information...." Clearly, the student's orderly approach to handling the problem served as the cue that enabled her to retrieve her existing knowledge of the library, which, then, helped her perform cognitive tasks more effectively.

As discussed above, researchers have started to unveil the role of affect and its interactions with cognition in the context of information behaviors. ${ }^{36}$ Through continuing efforts, our understanding of information behavior has moved a step forward to the understanding of how diverse affects play a role to create effective coping mechanisms for information searchers suffering from uncertainty ${ }^{37}$ The findings of the present study can augment this existing body of knowledge by uncovering a mechanism that explains how the cognitive aspect of critical thinking, an asset for successful information searching, can be hampered by library anxiety but can still be reinstated by positive affect of critical thinking. In this regard, the present study revealed not only a reciprocal relationship between critical thinking and library anxiety throughout but also the dynamic interactions between cognitive and affective aspects of critical thinking in the information search process.

Despite many useful outcomes, further research is anticipated because of some limitations of the study and to resolve several unclear pictures in the findings. One limitation relates to the study sample. The undergraduate students who participated in this study were recruited from an information literacy course that they took as either a required or an elective course. When it comes to the students who chose to take this course, they might represent the students who have greater needs in developing research skills than the normal population. This fact might have skewed the study results. In fact, the participants of this study were found to have lower than average levels of critical thinking dispositions compared to the normative sample that was reported by the CCTDI developers. Thus, the findings of this study should be read with this sample characteristic in mind.

In addition, because this study is the first study that investigated the dynamic 
interactions between critical thinking and library anxiety, the interactive model identified in this study should be further validated by a future study. In particular, while the model presents Stage 5 ("CT Skills Reinstated") and Stage 6 ("LA Diminished") in a separate sequence, the two stages appeared almost simultaneously in the student narratives. However, this sequence should be examined further because the seemingly concurrent appearance may, in fact, occur sequentially. The data collected for this study did not allow the researcher to determine the sequence due to the limitation of somewhat summative reports of past experience in the present study. Also, Stage 7 ("Task-relevant Behavior Performed") was assumed based on participants' subjective reports rather than objective actual evaluations of the task relevance. The aforementioned limitations warrant future studies using different data collection techniques, such as keeping diaries or longer-term observational techniques, to further clarify the last three stages of the model and to enhance the generalizability of the findings of the current study.

\section{Conclusions}

Higher education institutions have come to recognize information literacy as a key educational component in preparing their students in this fast-changing 21st century. ${ }^{38}$ As Kuhlthau once pointed out, "Librarianship for the information age goes beyond services for locating information to creating services for assisting students in the process of learning and using information they have located." ${ }^{39}$ This remark suggests a holistic approach to teaching information literacy that incorporates cognitive, affective, and behavioral aspects of learning. It was very interesting to note immense emotional challenges that students, the Millennials or Generation $\mathrm{Y}$ who are considered to be very competent and comfortable about their online-networked environment using Blogs, MySpace, and every other information technology every day, yet became so uncomfortable, confused, and intimidated in an unfamiliar, huge academic library.

With regard to the development of library skills, it seems that confidence breeds competence and vice versa. Each half of the cycle strengthens the other as the cycle repeats. If the instruction librarian undermines a student's self-confidence, it also undermines his or her competence at the research task. Therefore, it will be important for librarians to be equipped with this knowledge of the interaction between cognition and affect and to develop instructional skills accordingly. This will help librarians to prepare to be positive enablers for students in developing research skills.

With increasing knowledge about the affective domain of information behavior, the findings of the current study can offer practical implications for teaching information literacy in general and critical thinking specifically. Despite the general notion that teaching critical thinking involves cognitive activities only, this study showed the importance of the affective domain of critical thinking. Thus, instruction librarians should teach critical thinking dispositions to promote positive emotions while teaching library anxiety as a natural part of learning process in order to reduce negative emotions.

Concluding this report, several strategies can be suggested for instruction librarians who teach critical thinking dispositions. First, instruction librarians could teach students in a direction to support them to feel a greater level of confidence about their own reasoning processes and cognitive abilities. In addition, the librarians could create a learning environment that encourages intellectual curiosity and emphasizes the value of learning so that students could build the habit of being persistent when facing intellectual challenges. Finally, the instruction librarians could encourage students to employ diligent, focused, and systematic approaches when facing 
problems. These endeavors to equip students with strong, positive dispositions toward their critical thinking skills will help students effectuate their critical thinking skills and, ultimately, prepare them as capable lifelong learners.

\section{Notes}

1. Peter A. Facione, Critical Thinking: A Statement of Expert Consensus for Purposes of Education Assessment and Instruction, Executive Summary, "The Delphi Report" (Millbrae, Calif.: California Academic Press, 1990).

2. Association of College and Research Libraries, Information Literacy Competency Standards for Higher Education, 2000. Available online at www.ala.org/ala/acrl/acrlstandards/standards.pdf. [Accessed 5 September 2006].

3. Angela Weiler, "Information-Seeking Behavior in Generation Y Students: Motivation, Critical Thinking, and Learning Theory," Journal of Academic Librarianship 31, no. 1 (2005): 46-53.

4. Gary Marchionini, Information Seeking in Electronic Environments (Cambridge: Cambridge University Press, 1995).

5. Sonia Bodi, "Collaborating with Faculty in Teaching Critical Thinking: The Role of Librarians," Research Strategies 10 (1992): 69-76.

6. Ethelene Whitmire, "Development of Critical Thinking Skills: An Analysis of Academic Library Experiences and Other Measures," College \& Research Libraries 59, no. 3 (1998): 266-73; Ethelene Whitmire, "Academic Library Performance Measures and Undergraduates' Library Use and Educational Outcomes," Library E Information Science Research 24 (2002): 107-28.

7. Peter A. Facione, "Critical Thinking: What It Is and Why It Counts. 2004 Update," 2004: 8. Available online at www.mdaa.org.au/publications/manual/app2.pdf. [Accessed 5 September 2006].

8. Peter A. Facione, Noreen C. Facione, and Carol A. Giancarlo, "The Disposition toward Critical Thinking: Its Character, Measurement, and Relationship to Critical Thinking Skill," Informal Logic 20, no. 1 (2000): 22.

9. Peter A. Facione, Carol A. (Giancarlo) Sanchez, Noreen C. Facione, and Gainen Joanne, "The Disposition toward Critical Thinking," Journal of General Education 44, no. 1 (1995): 1-25.

10. Lloyd A. Kramer and Martha B. Kramer, "The College Library and the Drop-Out," College $\mathcal{E}$ Research Libraries 29 (1968): 310-12; Anthony J. Onwuegbuzie and Qun G. Jiao, "Information Search Performance and Research Achievement: An Empirical Test of the Anxiety-Expectation Mediation Model of Library Anxiety," Journal of the American Society for Information Science and Technology 55 (2004): 41-54.

11. Constance A. Mellon, "Library Anxiety: A Grounded Theory and its Development," College $\mathcal{E}$ Research Libraries 47 (1986): 161-65.

12. Anthony J. Onwuegbuzie, Qun G. Jiao, and Sharon L. Bostick, Library Anxiety: Theory, Research, and Applications, Research Methods in Library and Information Studies, no. 1 (Lanham, Md.: Scarecrow, 2004).

13. Nahyun Kwon, Anthony J. Onwuegbuzie, and Linda Alexander. "Critical Thinking Disposition and Library Anxiety: Affective Domains on the Space of Information Seeking and Use in Academic Libraries," College \& Research Libraries 68, no. 3 (2007): 268-78.

14. Paul A. Facione and Noreen C. Facione, The California Critical Thinking Dispositions Inventory (Millbrae, Calif.: California Academic Press, 1992). ety."

15. Kwon, Onwuegbuzie, and Alexander, "Critical Thinking Disposition and Library Anxi-

16. Sharon L. Bostick, "The Development and Validation of the Library Anxiety Scale" (Ph. D. diss., Wayne State University, 1992).

17. Kwon, Onwuegbuzie, and Alexander, "Critical Thinking Disposition and Library Anxiety."

18. Onwuegbuzie, Jiao, and Bostick, Library Anxiety; Nahyun Kwon, "Library Anxiety and Library Anxiety Scale in the Digital Library Environment," Journal of the Korean Society for Library and Information Science 38, no. 2 (2004): 29-47.

19. Doris J. Van Kampen, “Development and Validation of the Multidimensional Library Anxiety Scale," College \& Research Libraries 65, no. 1 (2004): 28-34.

20. Snunith Shoham and Diane Mizrachi, "Library Anxiety among Undergraduates: A Study of Israeli B. Ed. Students," Journal of Academic Librarianship 27, no. 4 (2001): 305-11.

21. SPSS 13.0 for Windows (Chicago: SPSS Inc., 2004).

22. Peter A. Facione, Noreen C. Facione, and Carol Ann F. Giancarlo, The California Critical 


\section{Critical Thinking and Library Anxiety among Undergraduate Students 131}

Thinking Disposition Inventory, CCTDI Test Manual (Millbrae, Calif.: California Academic Press, 1998).

23. Kwon, Onwuegbuzie, and Alexander, "Critical Thinking Disposition and Library Anxiety."

24. Mellon, "Library Anxiety."

25. Diane Nahl, "Affective Load," in Theories of Information Behavior, eds. K.E. Fisher, S. Erdelez, and L.E.F. McKechnie (Medford, N.J.: Information Today, 2005), 39-43.

26. Carol C. Kuhlthau, Seeking Meaning: A Process Approach to Library and Information Services, 2nd ed. (Westport, Conn.: Libraries Unlimited, 2004).

27. Nahl, "Affective Load," 42.

28. Kwon, Onwuegbuzie, and Alexander, "Critical Thinking Disposition and Library Anxiety."

29. Kuhlthau, Seeking Meaning.

30. Whitmire, "Development of Critical Thinking Skills."

31. Kwon, Onwuegbuzie, and Alexander, "Critical Thinking Disposition and Library Anxiety."

32. Carol C. Kuhlthau, "Information Search Process: A Search for Meaning Rather Than Answers." Available online at www.scils.rutgers.edu/ kuhlthau/Search\%20Process.htm. [5 September 2006].

33. Neil Howe and Bill Strauss, Millennials Rising: The Next Great Generation (New York: Vintage Books, 2000).

34. Nahl, "Affective Load."

35. Alice M. Isen, Kimberly A. Daubman, and Joyce M. Gorgoglione, "The Influence of Positive Affect on Cognitive Organization: Implications for Education," Aptitude, Learning, and Introduction. Volume 3: Conative and Affective Process Analyses, eds. Richard E. Snow and Marshall J. Farr (Hillsdale, N.J.: Lawrence Erlbaum Associates, 1987), 143-64.

36. Isen, Daubman, and Gorgoglione, "The Influence of Positive Affect on Cognitive Organization"; Kuhlthau, Seeking Meaning.

37. Nahl, "Affective Load."

38. Association of College and Research Libraries, Information Literacy Competency Standards for Higher Education.

39. Kuhlthau, "Information Search Process: A Search for Meaning Rather Than Answers," 8.

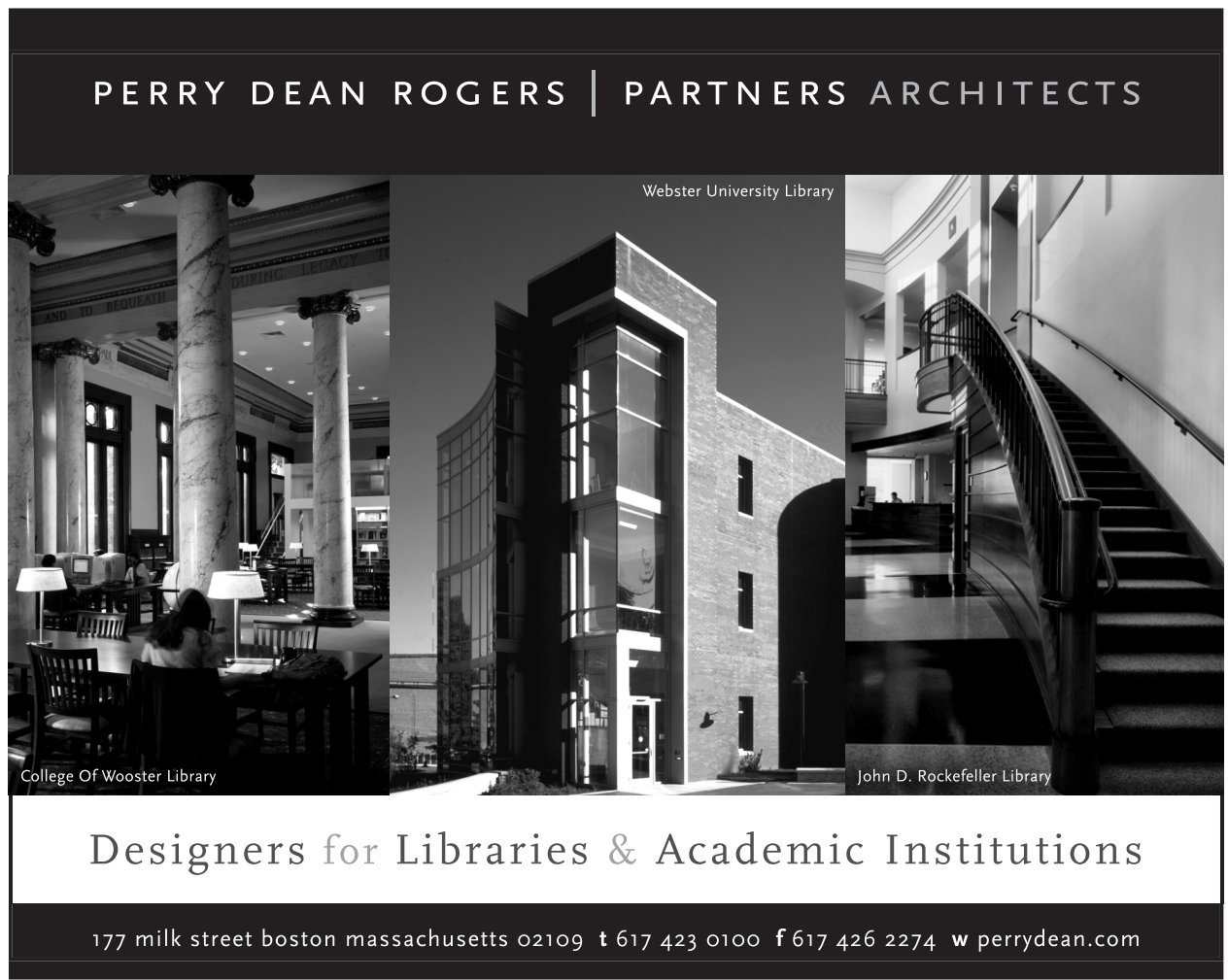

